\title{
Functional Adult Literacy: The Influence on Women's Improved Health Promotion Behaviours in Apac District, Northern-Uganda
}

\author{
Judith Abal Akello ${ }^{1,2^{*}}$ Peace Musiimenta ${ }^{2}$ \\ 1. Department of Business Management Lira University P.O Box 1035, Lira-Uganda \\ 2. School of Women and Gender Studies, Makerere University, P. O box 7062, Kampala, Uganda \\ * E-mail of the corresponding author: judithakello@yahoo.com
}

The research is financed by DAAD (German Academic Exchange Service) No. 91560790

\begin{abstract}
This article is about women's experiences of Functional Adult Literacy (FAL) as a means to their improved Health Promotion Behaviours in Apac District, Northern Uganda. The qualitative study of 29 participants aimed at examining women's improved well-being resulting from using their acquired FAL knowledge and skills to participate in health promotion behaviours. The study was informed by Kabeer's agency theory and Freire's literacy perspective which argue on the element of conscientisation or awareness by making marginalised nonliterate's agents of promoting health behaviours. The findings revealed that from the practical skills, the women experienced more confidence, increased awareness and understanding on health-related issues and improved well-being. Therefore, the study recommends that the Ministry of Gender, Labour and Social Development (MoGLSD), International Donors, Non-Governmental Organisations (NGOs) and Civil Society should ensure prioritisation, support and implementation of FAL training.
\end{abstract}

Keywords: Women, Practical learning, Participation, Well-being

DOI: $10.7176 /$ RHSS/11-8-07

Publication date: April $30^{\text {th }} 2021$

\section{Introduction}

United Nations Educational, Scientific and Cultural Organisation [UNESCO] (2015) strongly consider education as a human right that must be accessed throughout life. Likewise, the Incheon Declaration, the Sustainable Development Goal (SDG) 4 and the Education 2030 Framework for Action unanimously agreed on the importance of education. The debate pointed to the fact that all individuals (women, men, girls and boys) through multiple, flexible pathways and entry points must at least possess some basic functional literacy and numeracy skill in order to achieve some level of meaningful individual and communal development. According to UNESCO (2006), a literate person is one who can, with understanding, both read and write a short simple statement, while a functionally literate individual is one who is able to improve upon his/her quality of life and make informed decisions due to his/her acquired literacy skills. Functional literacy, therefore, lays emphasis on the utilisation of literacy skills acquired to change one's life, while a literate person is measured by his or her ability to read and write (Ministry of Gender, Labour and Social Development [MoGLSD], 2007). Thus, in addition to acquisition of reading, writing and numeracy skills, many developing countries have adopted the strategy of training nationals in development-oriented skills and knowledge. Hence, the functions for which the literacy skills are learnt can determine the programme by which it is obtained, particularly, Functional Adult Literacy (FAL) programme is focused on skills for women to successfully participate in health promotion behaviours and improve their well-being.

Additionally, scholars and governments in both the developing and developed countries have for long suggested a strong link between functional adult literacy and the influence in health promotion behaviours of women who participated in the training. Subsequently, in 1966, UNESCO initiated the Experimental World Literacy Programme to "test and demonstrate the economic and social returns of literacy" (UNESCO, 1974, p. 68).

In Uganda, functional version of literacy was introduced, promoted, and co-financed by Uganda government and UNESCO who played a major role in revamping of FAL training in Uganda in 1983, 1987, and 1989 (Hanemann, 2017; Okech \& Carr-Hill, 2001). The target group comprised of specifically, men and women, older people and youths who had missed the chance of benefiting from formal education during childhood. The FAL programme 
which was implemented in 8 districts in 1992 expanded to 22 districts by 1999 . Therefore, in response to national adult literacy policy, FAL training primer/curriculum emphasised the integration of basic reading, writing and numeracy with functional skills in order to empower the adult trained people for improving their livelihood and well-being (MoGLSD, 2015).

Global statistics show that, although literacy has been high on the development programme over the past decades, the latest literacy figures display that, out of the 750 million adults, $63 \%$ of non-literate population whom are women, still lack basic reading and writing skills (UNESCO Institute for Statistics [UIS] (2017). In addition, UIS report indicate that, while countries such as, Algeria, Oman, Rwanda and Uganda have made the greatest progress to close gender gap between young (15- to 24-year-olds) males and females over the past decades, the female elderly literacy rate is less than one-third the male elderly literacy rate. Women's non-literacy status explains their disadvantage and limited awareness on modern health promotional practices (Freire, 1970). Imam et al. (2017) argued that non-literate women in Faisalabad were less aware of health promotional practices such as water hygiene compared to literate ones. Hanemann's (2017) evaluation reports indicate that non-literacy was negatively linked to women's awareness on hygiene and related ailments. This implies that reading, writing and numeracy skills for adult women should be strengthened to meet the SDG 4 Declaration and Education 2030 Framework stated above. This article therefore argues that the literacy skills acquired influence the health promotion behaviours of adult women who missed the opportunity of formal education.

In the last 20 years, national and international debates on the status of women and their high levels of poverty as well as non-literacy have compelled development practitioners to consider integrating women into development processes of nations (Akello, Lutwama-Rukundo, \& Musiimenta, 2017; Olaleye, 2008). These debates have indicated that a considerable development potential is locked up in the $63 \%$ (women) of the non-literate people globally. Therefore, to unlock women's potential and improve their awareness on health promotion behaviors, FAL should be used as a means to improve their well-being (Hanemann, 2017).

\subsection{Problem Statement}

While many developing countries are focusing on educating their population, there are still many women that lack literacy skills, and they continue to be perceived socially and economically handicapped. As expressed in SDG 4 that aims at ensuring an inclusive and equitable quality education and promoting lifelong learning opportunities for all, inability to read, write or understand literature available for economic and social progress disadvantages non-literate women. Non-literate women's inadequate ability to obtain and understand vital information has been associated with lower self-esteem, confidence and low participation health promotion behaviours (Akello, Lutwama-Rukundo, \& Musiimenta, 2017; Hanemann, 2017; Imam et al., 2017; Kabeer, 2005). Moreover, it is believed that non-literate women have limited skills in maintaining the home hygiene and health of their families.

Although scholars and development practitioners have for long suggested a strong link between functional adult literacy training and the influence on health promotion behaviours, scholarship and government reports in Uganda and beyond indicate that many women are still non-literate (UBOS, 2016; UIS, 2017). Consequently, the lack of literacy skills among these women continues to limit their full potentials and affect their participation in development.

To reduce on the imbalance of high numbers of women without literacy skills, free FAL training was introduced into communities. While significant numbers of women turned up for training, little attention has been given to finding out how they have benefited or not benefited from the training in the perspective of health promotion behaviours. Therefore, this study aimed at addressing this knowledge gap.

\subsection{General Objectives}

The main objective of this study was to explore the influence of functional adult literacy training in promoting the health behaviours of women participants in Apac District.

\subsubsection{Specific Objectives}

i. $\quad$ To analyse the women's experiences in Apac District prior to their training in FAL.

ii. To establish whether there were any changes in women's health promotion behaviours accruing from their training in FAL. 


\subsection{Research Questions}

The key research question was: Have the women participants in Apac District promoted health promotion behaviours from the skills acquired in FAL training?

The research question was divided up into further questions, thus:

i. What were the women's experiences in Apac District prior to their training in FAL?

ii. How did training in FAL change the health promotion behaviours of women in Apac District?

\subsection{Theoretical Underpinning}

The study was informed by agency theory from Kabeer's (2005) viewpoint and Freire's (1970) literacy perspective.

\subsubsection{Freire's Literacy Perspective}

Freire's literacy theory is founded on notions of agency and inclusion. In the acquisition of education, Freire a Brazilian educationist emphasised conscientisation, as a deliberate effort of a teacher to open the minds of the learners to discover the world within which they live. Conscientisation is the process where people are made aware of and understand their surroundings and the overriding social structures, for example, patriarchy that oppresses and marginalises, particularly the women (Freire, 1970; Kotsapas, 2010). Freire's teaching methodology stresses that adult literacy could contribute to social improvement in the unjust societal power structures.

Freire states that literacy should not only impart basic skills in reading, writing and calculation, but also contribute to effective functioning and development of an individual, a group and the community (UNESCO, 2006). Freirean literacy perspective also supports agency theory which emphasises individual and collective agency through the notions of 'conscientisation' or awareness creation and dialogue, as tools for making marginalised people agents of social change and engagement in health promotion behaviours. Conscientisation gives women the opportunity to recognise the social challenges about their lives. This is in line with what Freire \& Macedo (1987) explain that lack of consciousness of the real world, limited social awareness and critical inquiry can impede social change, especially for the non-literate women. Accordingly, women who have acquired FAL skills and understanding of the social world should act as functioning members in their families and community.

\subsubsection{Kabeer's Agency Theory}

Kabeer, a feminist scholar has continued to advance that agency is a person's ability to define his or her strategic life choices and act upon them even if there are others that oppose (Kabeer, 2005). She holds that women should engage in transformative development as active agents not passive participants. Kabeer, however, argues that for many societies, institutional biases, (customary, cultural ideological norms and values) restrict many women's ability to make such choices. Her perception of women's less ability to make choices is indicative of the need for a strategy to bridge gender gaps between the levels of both formal and informal institutions through a joint intellectual model. Kabeer (1999) argues that bridging gender gaps requires changes that serve women's strategic gender interests, for example, abolition of discrimination of the preference of educating or training boys to girls.

Agency, according to Kabeer (2005, p.15) can be "passive" or "active". The former is "action taken when there is little choice" and the latter is "purposeful behaviour". Hence, the conception of active agency suggests that FAL trained women are expected to become active agents in health promotion behaviours.

Further, Kabeer (2005) emphasises the power of education and literacy to ignite women's ability and social inclusion. Kabeer further argues that literate women must have the ability to question, analyse and challenge the patriarchal structures that reproduce constraints and inequalities in their lives. Therefore, depriving women of well-being is a matter of social injustice for them as individual social actors.

The agency theory significantly explains women's active participation. First, the women's development as paramount self-driven shows how individual women actively participate in health promotion behaviours and improvement of their well-being. Agency theory, therefore, is relevant to this study that focuses on how women 
who are FAL beneficiaries actively participate or fail to become agents in promoting the health behaviours and improvement of their well-being.

\section{Literature Review: An Overview}

\subsection{Non-Literate Women's Experiences on Health Promotion Behaviours}

Non-literate experiences are a result of negative perceptions and gender relations which lead to inequality and deny the women equal opportunities as men, for example, training, participation in community events and income generating activities (Kotsapas, 2010). Negative aspects of perception reveal, but are not limited to automatic negative thoughts, lack of self-esteem, negative attitude of self/ others/ world/future, hopelessness, helplessness, worthlessness, inferiority, inadequacy, fear, sense of failure, and identification with the oppressor/dominator (Wetzel, 2016).

International organisations and NGOs have recognised the problems that non-literacy poses and agreed upon the need to eradicate non-literacy and to promote ways of helping individuals, especially women to acquire a basic set of skills (UNESCO, 2021). In addition, UNESCO noted that the literacy skills acquired enables women's better ability to participate in improved child and family health and nutrition; reduces poverty and in turn expands life opportunities.

A report on Uganda notes that specifically, adult women are suffering from serious discrimination on the basis of gender and age, a factor which compounds their problem of poverty (Findsen \& Formosa, 2016; Sleap, 2010). The same study further noted that adult women contribute, for example, in terms of taking care of HIV/AIDS orphaned grandchildren, yet at the same time they are experiencing many health-related problems and poverty. The status of women clearly implies that despite being old and non-literate, they still require FAL training to relieve them of the burden, for instance, their children's health. Therefore, literacy is considered essential for understanding, interpretation as well as easy communication; and it is difficult to fit well in the community if one is non-literate (Hasaba, 2012; UNESCO, 2019).

\subsection{Health Promotion Behaviours and Improved Well-being of Literacy Training}

Literacy is considered significant in several ways. Both international and national NGOs have recognised that training or education eradicates poverty. They have agreed on the need to eradicate non-literacy by promoting ways to help individuals, especially women to acquire a basic set of skills (UNESCO, 2013).

Literacy has been linked to a different health outcome and improved family and community well-being (Merriam $\&$ Kee, 2014). Findings in Nepal indicate that women who participated in literacy programmes can understand health issues better and use the available health services compared to their non-literate counterparts (Niraula, 2011). Therefore, the aspect of women's positive influence on improved health conditions suggest that literacy skills are significant to women's improved well-being.

According to Blunch (2013), a study in Ghana found that literacy directly increased health knowledge of mothers and health productivity. Blunch's report is supported by Langer et al. (2015) who argue that training for women protects their health and boosts their productivity. In that regard, increased female literacy has the potential to contribute to better child care, nutrition, improved health or well-being in the family. That is to say that a literate mother is also more likely to have the ability to understand health related issues on her own when it comes to health promotion behaviours, which in turn improves their productivity as well as improved well-being.

While similar claims about the effect of literacy on women have also been reported in Uganda in general, studies specifically focusing on literacy projects in Apac District are difficult to find. Nonetheless, Hanemann (2017) and Okech et al.'s (2001) report in Uganda revealed that literacy programmes benefited the learners with practical knowledge, in terms of adoption of better health practices, especially through better personal and environmental sanitation. Likewise, Rogers (2008) conducted a process review of Uganda's FAL in Kalangala and Buvuma Islands and reported that the primary value of the FAL classes to the learners particularly women lie not in their literacy learning but in their functional activities. This implies that women's literacy skills are associated with improved access to health information, outcome, quality of life as well as their well-being. This is in line with what Freire \& Macedo (1987) explain that lack of consciousness of the real world, limited social awareness and critical inquiry can impede social change, especially for the non-literate women. Freire is further supported by Kabeer (2005) which emphasises literacy as a powerful tool to ignite women's ability and social inclusion. Accordingly, women who have acquired ability in reading, writing, numeracy and understanding of 
the social world should act as functioning members in their families and community.

\subsection{The Gaps in Literature}

The literature above indicates that, while similar claims about the effect of literacy on women and improved health promotion behaviour have also been reported in Uganda in general, studies specifically focusing on literacy projects in Apac District are difficult to find. The current study fills these gaps by exploring and understanding the influence of functional adult literacy training in promoting the health behaviours of women participants in Apac District.

\section{Method}

Using the qualitative interpretive framework, the study used phenomenological method and case study research design, while focusing on FAL-trained women. Phenomenological method to qualitative research focuses on the commonality of lived experiences of a group of individuals in order to arrive at a description of the nature of the particular phenomenon (Creswell, 2013; Fossey, Harvey, McDermott, \& Davidson, 2002). Phenomenological approach helped the researcher to interpret the meanings of individual's lived experiences which suited this study. Denscombe (2014, p.2) contends that interpretivism is concerned with seeing "social reality as something that is subjectively constructed by people's thoughts and actions". In the interpretive paradigm, the aim of the researcher to understand the subjective meanings of study participants is important (Goldkuhl, 2012). This implies that social researchers must always be part and parcel of the social reality they are exploring and interpreting. In this study, the design enabled the researcher to explore women's lived experiences with skills gained from FAL programme, whether and in what way women participants in Apac District improved their health promotion behaviours from skills acquired from FAL training. The choice of a case study design was preferred because it creates closeness to real life situations and generates a wealth of information on multiple sources of data or evidence from the life experiences of participants (Yin, 2013).

\subsection{Study Area and Population}

The study was conducted in Apac District found in the Lango region of Northern Uganda and an estimated population of 368,626 (180,995 males and 187,631 females) indicating more women than men in the population (UBOS, 2017). In addition, UBOS report indicate that the major economic activity in Apac is farming and it has the highest supply of crop production in the country. For instance, the district of Apac was reported to have the highest cassava production of the country estimated at 239,932 tonnes compared to other districts, such as Masaka (64,965 tonnes), Tororo (174,962 tonnes) and Hoima (60,932 tonnes) respectively (UBOS, 2015). To support economic activity, particularly women, the government of Uganda implemented the FAL training programme in 8 districts, including Apac, Hoima, Kabarole, Mbarara, Mukono, Mpigi, Kamuli and Iganga (Nsekaki, n.d). This implies that training for women is crucial to protect their health, boost their productivity as well as improve their well-being. The national report indicating Apac as a pilot district for FAL training, the time, financial and personal expenditures involved in collecting data influenced my choice as a study area.

\subsection{Study Population and Sample Selection}

The study population comprised of 29 participants (24 participants that graduated from FAL training, a case study, Focused Group Discussion (FGD) and 3 Key Informants). The Key Informants comprised an official from MoGLSD at the position of Principal Literacy officer, and Community Development Officers - from both the district (DCDO) and the sub- county levels (CDO). These officials were the overall coordinators of FAL training programme in the entire district and at a sub-county level. Whereas the study was on women's lived experiences of as beneficiaries of FAL training, a purposive discussion with a group of men was conducted. These included men that were family members or had close relation with the women participants who had engaged in FAL training. The purpose of men's inclusion was to capture their voices and perceptions on the training programme. Also, it was in response to the majority of the women who expressed interest and opinion that the discussion should also include men. Twenty-nine (29) participants were considered an appropriate sample, because of the rigour in qualitative research data in-depth analysis (Creswell, 2011). The participants were purposively selected which is commonly used in qualitative research to select the study participants. This sampling involves selecting research participants that have knowledge of the research topic and can give detailed and rich information that is suitable for qualitative research (Creswell, 2013). 
A sample of 29 participants were selected as follows:

- 24 participants that graduated from FAL training (20 women and 04 men)

- A case study- A woman

- FGDs were selected as follows:

- $\quad 09$ FAL trained participants (06 females and 03 males)

- 3 Key Informants were selected as follows:

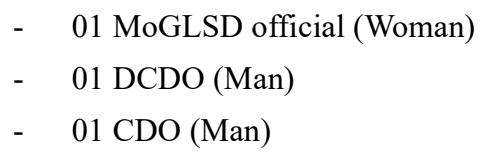

The participants comprised of those that had graduated from FAL in 2013, (the study period between 2011-2013) for the purposes of getting up-to-date information about women's experiences in FAL training in relation to health promotion behaviours. Moreover, participants that enrolled in 2014 had not yet completed their three levels of training. Purposive sampling helped me to select the participants that had the best knowledge and experiences in FAL training programme.

Sampling of participants stopped at the point of saturation. Out of the 29 participants, by the time I interviewed a half of the participants, they were giving me exactly the same answer. According to Mason (2018), saturation is when collection of the new data does not shed any further light on the issue under investigation, guided by both interviewing and sampling. Such a point is a diminishing return to a qualitative sample which signifies that the data collection process is complete or near completion (DiCicco-Bloom \& Crabtree, 2006).

\subsection{Data Collection and Analysis}

In this study, four qualitative methods of data collection were used: in-depth interviews, a case study, FGD and observations. A face-to-face interview was conducted using open-ended questions from an interview guide. Hesse-Biber (2013) endorses in-depth interview for researchers seeking to understand the lived experiences of the individual. These techniques were useful in understanding the divergent experiences of women in health promotion behaviour before and after participating in FAL training. The case study was used to obtain a rich, detailed and contexualised information about women's experiences of FAL training and influence on health promotion behaviour. FGD provided an open discussion on women's experiences before and after FAL training and the influence on health promotion behaviours. Direct observation helped the researcher in understanding the meaning of participants' experiences and interpreting the non-verbal responses and how the participants manage and improve upon their well-being in the family and the community where they lived. Triangulation of methods enabled the researcher to check data collected using one method of another method which boosted the richness of data collected in a case study research deign. While case study may limit themselves to descriptive, exploratory objectives or even inability to generalise conclusions in the conventional sense, Yin (2013) recommended triangulation in order to generalise findings for a good case study.

Guided by Creswell's (2007) deeper analysis of qualitative data analysis, data collection and report writing process goes together. This study followed Creswell's suggestion which include: data management phase; generative phase; interpretive phase; and representing and theorising phase. Primary data was analysed through a detailed process that produced themes from the textual data and observations noted. During the generative and interpretive phase, qualitative data was coded using qualitative content analysis for Key Informant and in-depth interviews, while reading the whole transcripts numerous times to get logic in relation to the specific data on health promotion behaviours. The data generated two themes, that is, non-literacy and women's experiences of health promotion prior to FAL training and women's improved health promotion behaviour after FAL training.

\subsection{Ethical Considerations}

Given the sensitive nature of the study, the researcher endeavoured to protect the research participants by assuring them that there was no negative implication for their participation in the course of the research (Creswell, 2013). During fieldwork, the informants were briefed on the information about the study and consent was sought from each participant prior to the in-depth interview and use of recording devices and camera. 
All those who participated understood that identities were hidden with pseudonyms or anonymous names based on official titles for Key Informants for purposes of confidentiality. Previous studies have shown that anonymity should be respected (Simons 2009; Marshall and Rossman 2011; Rule and John 2011). Hence, this study only used pseudonyms or anonymous names to report direct quotes from the participants and information obtained from them was kept confidential. Participants were also briefed about the purpose of the study and they were also informed that the result of this study shall be published.

\section{Findings and Discussion}

Findings are discussed under the following sections; Non-literacy and Women's Experiences of Health Promotion Prior to Training in FAL; and Literacy and Women's Experiences of Health Promotion Behaviour after FAL training.

\subsection{Non-literacy and Women's Experiences of Health Promotion Prior to Training in FAL}

this study delves into three key aspects of hygiene that the non-literate women identified as crucial: water hygiene, sanitation and physical homestead environment.

Water Hygiene: The importance of maintaining clean and safe drinking water was emphasised. However, findings indicated that before FAL training several of the non-literate women paid little attention to water hygiene. To illustrate this matter, Filomena explained that,

For water hygiene, we just cleared the grass and drank water from the middle of the swamp thinking it was clean. Although, we saw "olwilwiny" [worms] in the water, we would clear the worms away using the calabash and then scoop the water that had no worms in it. Anyway, we used to complain about stomachache but there was no option.

Arao added that,

On hygiene, specifically water, we used water from the well which was sieved locally using a piece of cloth. But whenever we felt lazy to sieve, we would not bother. We would drink it like that. But sometimes, some people suffered from stomachache. I guess ... it was because the tablecloth was dirty.

The two accounts above (Filomena and Arao), "cleared the grass" and "water from the well ... sieved locally using a piece of cloth" are remarks unmindful of the impact of drinking dirty water. However, the experiences of stomachaches reveal that the methods of water management used by the women were inadequate and could not prevent incidences of ailments. Also, statements such as, "there were no option" and "We would drink it like that" by Filomena and Arao serve to emphasise the limited awareness by the non-literate women of the available methods of managing water hygiene. The above findings corroborate with the previous findings by Imam et al. (2017) which revealed that non-literate women in Faisalabad were less aware of water hygiene practices compared to literate ones. Non-literacy was limiting these women's awareness of modern health promotional practices (Freire 1970). And yet, without the introduction of these methods to the women in the FAL training that they later got, their agency to improve upon drinking water hygiene remained dormant. The women's expressions above agree with UNESCO (2008) and Hanemann's (2017) evaluation reports which indicate that non-literacy was negatively linked to women's awareness on hygiene and related ailments such as "stomach ache”. This demonstrates women's less ability to manage their health or hygiene due to their non-literacy status despite their indigenous knowledge. Hence, Filomena and Arao's expressions reflect the need that the nonliterate women had for the strengthening of skills and abilities to purify consumable water within their communities, as a prerequisite to managing ailments.

Sanitation: This comprised of hygiene within households in terms of toilets, bathrooms, shelters and the general home environment as well as personal hygiene, several experiences were highlighted. In this respect, Filomena explained that,

About a toilet, ah, even if we were sensitised by the Village Health Team (VHT) and secretary for health in the LCI leadership..., we did not care as long as no one was seeing us. You know...previously we were ignorant about the use of health hygiene ... as there were no toilets, we used to go and defecate in the bush or would dig holes in the ground in the garden.

Otwila added that,

Prior to FAL, we were sensitised by office of CDO and Local Council (LCI) for all the homesteads to have 
proper erected toilets and bathroom or shelter. We thought they were forcing us... my family and I continued to bathe anywhere as long as no one was seeing us. We had no properly erected shelter. For the toilet, we resorted to using holes in the anthill. My family experienced continuous stomach aches, the problem of diarrhoea was common and this costs me money for treatment.

Yet, Arao, explained that, “...there were government by-laws that we should have properly erected shelters and toilets. Few families had temporary pit latrines...”.

According to Filomena, Otwila and Arao, no attention was being given to the concern by government that communities within which they lived should improve upon their hygiene, as exemplified by actions of going to anthills or making holes in the grounds around their homesteads. However, the women's disregard of government efforts seemed to emanate from their lack of full understanding of why there was need to improve upon their hygiene. The women's statements, "even if we were sensitised", "thought they were forcing us" and "government by-laws" imply the women's insufficient awareness of the importance of sanitation and that is why they mistook, for example, the "government by-laws" for a punishment. Consequently, the expenses incurred by Otwila on treatment of stomach-aches point to the necessity of basic literacy skills. The skills would enable the women to read more about hygiene and sanitation, in order to enhance the ability to improve upon the general well-being of their households and communities. This concurs with what Freire (1970) earlier on referred to as lack of consciousness of real-life experiences.

Physical Homestead Environment: The women were probed on how they managed their homestead environmental hygiene. This was especially on the aspects to do with the yards, flooded or stagnant water and rubbish. Corina, using her personal experience explained that,

I lacked the awareness that malaria was caused by unhygienic environment in my home, like stagnant water and open rubbish dump site. I had many mosquitoes in my home and this greatly affected my sleep as well as for the family. My family constantly suffered from Atipa [malaria] which affected participation in family work and ability to generate income.

Atala, an 83-year-old widow who had no family members or dependants, a peasant farmer, and household headed by her married step-son expressed that,

In my home, the things that a good and hygienic home environment must have, I did not have them. My compound was not swept clean daily; there was a lot of stagnant water near the kitchen where I washed utensils due to lack of proper water drainage... Although, we were being sensitised and given free mosquito nets through our sub-county to prevent being bitten by mosquitoes, my family still suffered constant mosquito bites and malaria... contrary to advice by VHT, I kept the grass in my compound tall for rearing goats.... I had less knowledge that a bushy homestead and unhygienic home environment breeds mosquitoes which leads to malaria.

The above interviews indicate that the women could not associate illnesses with poor homestead hygiene management. The women's statements, such as, "I used to suffer a lot from mosquitoes... Atipa [malaria]" and "suffered constant mosquito bites and malaria" just go to emphasise that the inadequate awareness that the women had. Corina and Atala's statements of lack of knowledge and awareness that "unhygienic environment" as well as "bushy homesteads" breed mosquitoes which causes malaria indicate the element of ignorance in the women. This corresponds with what Freire (1970) earlier on referred to as lack of conscientisation. The women's non-literacy kept them in a state of ignorance concerning very crucial health knowledge and practices. Consequently, the women and their families constantly suffered from "malaria". The women's non-literacy state continued to affect them in more significant ways. For instance, Ayuru narrated that her inability to read and understand written information contributed to improper management of hygiene as quoted below,

The office of the CDO organised sensitisation meeting on how to manage the drinking hygienically water through boiling, filtering and using chlorine tablets. The tablets were distributed by an NGO called The Aids Support Organisation (TASO) with the help of health assistants. Unfortunately, the project ended, and we had to buy the tablets from the shops. Despite the information circulated to us, being non-literate affected my life. I was unable to read and follow instructions on the packet of tablets used to treat drinking water that I bought from the shops. For us, the non-literate, we were advised to use the method of boiling water which takes time to cool but doesn't require instructions in case the health assistants were not available. I resorted not to treating drinking water. My family suffered from stomach problems due to unsafe water. The time I should be doing work, I am at the clinic. I constantly lost the little income. This affected my well-being.

Otwila argued thus:

Before I participated in FAL training, we were sensitised through our community leaders, for example, with the 
slogan "cilo kelo peko" [Poor hygiene begets problems]. However, there were notices on notice boards, such as "coron tye kan" [toilet is here] which I could not read ... I was also unable to identify male and female washroom in public places... I feared to ask... Sometimes, I used the bush as an alternative for the toilet...

Nampa's narration went as follows:

When I had not enrolled for FAL training, we often received information on hygiene from the office of the CDO and LCI during meetings, but I could not read notices in public places about hygiene in the local language that "log cingi iyo nge wot i coron" [wash your hands after visiting the toilet]. Dirt brings problems..., spreads disease such as diarrhoea and the result are death and poverty.

The statement by Ayuru, Otwila and Nampa about their inability to read, write and follow instructions denotes that although the women had basic knowledge of managing cleanliness, sometimes they missed out on the written information or notices due to being non-literate which affected their level of managing personal cleanliness. The women's concern about, "lost the little income", "I used the bush as an alternative for the toilet" as well as "death and poverty" suggests that non-literacy limited their ability to manage personal cleanliness and improve on their well-being. The above findings fit within Murtala (2013) and UNESCO's (2021) argument that literacy a driver for sustainable development in terms of enabling individual's greater participation in the improved child and family health and nutrition; reduces poverty and expands life opportunities. This indicates that women's non-literacy status hinders their ability to maintain the hygiene in their homes and physical home environment. which is a prerequisite for improvement of their families' well-being manage. This is in line with what Freire \& Macedo (1987) explain. They hold that lack of awareness of the real world requires a deliberate effort by the teacher to open the minds of the learners, to discover the world within which they live and effectively have the ability to function in the community. Therefore, the indigenous knowledge that Ayuru, Otwila and Nampa had demonstrated their latent skills upon which the FAL training built.

Disease Management: This study explored the women's ability to manage diseases within their families prior to being trained in FAL. Arao narrated that,

Prior to FAL, if one got "atipa" [malaria], we had no option, we would use the tree roots, namely, "gacia" [cassia] or "okello" ... For diarrhoea, we used to pound, boil and drink the tree roots from "te odugu" or "kongo anor".

Onyeko shared the following experience:

Before FAL, we used local salt distilled from ash to treat "ayila kom me imung" [fungal infection] which causes itching in women's private part. My condition would improve temporarily then re-occur.... I feared disclosing my problems. I lacked the knowledge on how to manage the ailment and I constantly suffered from the ailment...

Apilli said that she experienced difficulties in managing ailments due to her inability to interpret drug prescriptions. She explained that,

Prior to FAL, I used to mix up tablets. Whenever I was given prescriptions, I could not follow and understand the number of times to swallow tablets per day. One time, I nearly died because of under dose. Malaria was not getting cured, my husband had to spend more money buying an expensive drug.

The participants' views above reveal the substantial indigenous knowledge used in the management of diseases. Much as the research could not discover the botanical (English) names of some herbal medicines they referred to, the data suggests that Arao and Onyeko got some temporary solutions from the medicine. However, the women's comments, "we had no option" and "lacked the knowledge" appear to be the reason behind their choices of medication of the diseases. Being that they were non-literate and were not aware of other ways of treating diseases, they were left with such limited choice. However, Onyeko's testimony, "I feared disclosing my problems" indicates some frustration over the effectiveness of the remedies that the women were using in healing the diseases. The women seemed confused about what to do with the re-occurrence of the diseases. This situation, therefore, suggests that there is a need to integrate indigenous skills and knowledge of non-literate with systematic training to enhance the women's knowledge and ability to manage diseases. Agrawal's (2014) emphasises this in the argument that indigenous knowledge cannot be underrated, but should be supplemented with systematic training. Furthermore, a note should be taken of Freire's (1970) contention that adult literacy is crucial for marginalised people, particularly non-literate women. This is because many of the hardships in treating diseases that these women faced could have been resolved by seeking help from hospitals and reading instructions offered there. Therefore, while comparing the cost of indigenous knowledge to modern health approaches discussed above, this study indicated that the cost of indigenous knowledge in relation to nonliteracy was more expensive to manage diseases within the families. 


\subsection{Literacy and Women's Experiences of Health Promotion Behavior after FAL training}

In this section, women's improved participation in health promotion behaviours is discussed in terms of water hygiene, sanitation and physical home environment, family planning, immunisation and HIV/AIDS. The case below provides a general overview of improved women's participation in health promotion after FAL.

Case 1. Filomena's experience of Participation and Improved Health Promotion after FAL

Filomena, a 54-year-old widow, peasant farmer and community leader is now a volunteer in community undertakings after graduating from FAL programme. Despite having trained when she was in her midfifties, she explained how FAL skills has enabled her ability to participate in health promotion behaviours after FAL. She described that:

Because of FAL, I am now a member of Village Health Team (VHT). I oversee hygiene and sanitation by checking whether households are drinking clean water and the latrines are kept clean and not full and that there should be a house for animals, chicken, and bathroom and rubbish pit. I also sensitise the community on the importance and requirements of maintaining good water hygiene, sanitation and hygiene of physical homestead environment. ... this has improved on the management of hygiene and reduced on ailments such as stomach pain, diarrhoea, malaria and well-being in many of our households.

Currently, many women and myself take our children and grandchildren for immunisation and adhere to the schedules. After completion of FAL, I now sensitise the community, particularly, women to bring their children for immunisation services in designated locations and health centres. I also support the professional health workers in explaining the written information, for example, on reading charts written in the local language on the importance of immunisation to family members and the community. As a member of VHT, I also distribute essential drugs as well as sensitise the community on voluntary HIV/AIDS testing as well as family planning. As women, awareness, control over our health and productivity has improved. We now spend less money for medical treatment and this has reduced on our poverty.

The above case demonstrates that FAL skills have been linked to various health outcomes which include but are not limited to water hygiene, sanitation and hygiene within the homesteads, common diseases, HIV/ AIDS, immunisation and family planning. Filomena's statement about well-being depicts that literacy skills acquired reduced the occurrence and impact of major ailments that can cause illness but are preventable, particularly on women's lives. She acts as a key, village level contact person and able to control barriers, such as access to HIV/AIDS tablets, based solely on her FAL skills and motivation to improve upon the lives of the family and other members of the community. Studies have also reported that when you train a woman, she will introduce better health practices to her family and the community (Rothman, Yin, Mulvaney, Homer, \& Lannon, 2009).

Filomena's account of overseeing and sensitising the community on the significance of good hygiene and health management corroborates Kabeer's (2005) active agency perspective. Filomena's case further indicates that women who participated in FAL programme understood health issues better, used the available health services, which as result reduced on their poverty due to less expenses incurred on medical treatment. This is indicative of women's improved awareness on the significance of good hygiene and health management after FAL. It concurs with Freire's (1970) perspective of conscientisation of adult women through literacy training. Filomena's enhanced understanding concurs with an assessment report that literate parents understood correct medication, such as immunisation and dosing instructions compared to non-literate parents (Shields, McDonald, McKenzie, \& Gielen, 2016). The above case is consistent with findings of past studies by Hanemann's (2017), which indicate that on health-related awareness $47 \%$ of FAL graduates for example use family planning methods compared to $14 \%$ of non-literates in Uganda. The findings regarding Filomena's saved money for treatment, lessened poverty and improved well-being after FAL tally with Freire's literacy theory that women improved well-being within their homes can be enhanced through training (Freire \& Macedo, 1987). Hence, her positive influence on improved hygiene and health conditions suggest that literacy skills are significant to women's improved well-being.

An official from MoGLSD in support of how FAL has generally improved women's good hygiene and health practice concluded that, 
Women's personal and home hygiene has improved after FAL training. For example, they now have a separate house for the family; they have a bath shed, latrine, kitchen, plate stand and a house for goats and chicken. In turn, ailments such as stomach pain, diarrhoea and bilharzia have reduced and their medical expenses as well as have reduced. In addition, health seeking behaviour has improved. These days they go to the health centres and hospitals. They now immunise their children, test for HIV/AIDS unlike prior to FAL. Some women-graduates now practice the use of family planning because we have some of them who are still giving birth, for example, some of the communities we have visited have child mothers below 18 years. You know, FAL commences at 15 years...

Altogether, based on MoGLSD's assertion there was a general observation that women's FAL skills have been linked to a different health outcome and improved family well-being. Hence, ability to understand health issues and maintaining good health conditions shows that literate women can perform to the full capacity, for example, participation in productive work in terms of income generating activities which in turn improves their well-being.

\subsection{Conclusion}

The study established how FAL improved the well-being lives of trained women. Compared to non-literate women, the FAL trained women enhanced their opportunities to participate in health promotion behaviours. The women understood and appreciated the importance and the requirements of good hygiene and health promotion. The latter includes family planning, immunisation and HIV/AIDS, while the former includes water hygiene, sanitation and the physical homestead surrounding. These are indicators of improved well-being.

\subsection{Recommendations}

The study recommends that MoGLSD which coordinates FAL training in Uganda along with other departments, such as, international donors, NGO's and civil society, should ensure prioritisation, support and implementation of FAL training. For example, MoGLSD can connect FAL to group learning components, so that women are equipped to perform their roles more effectively.

MoGLSD needs to create awareness of the benefits of FAL training by starting with policy review and action plan for compulsory FAL training, particularly for the women.

\subsection{Further Research}

First, the research for this study was carried out in Uganda. Therefore, the lessons learnt from this study serves as a basis for future and comparative studies of FAL-trained women across Africa and beyond.

Future research could focus on the parity in health promotion behaviours between couples or families that have undergone FAL and those that have not in the context of developing and developed countries. Such a study would reveal the details of the benefits that FAL carries in empowering the learners.

Finally, this study recommends a review study, a monitoring mechanism to this study so that at regular intervals, for instance, every two years, to ascertain the well-being of the participants in this study. There might be very interesting findings for policy review of women's opportunity in FAL training programme, participation in health promotion behaviours and improvement into their well-being.

\subsection{Limitations of the Study}

The researcher faced the following limitations during the field work:

The first challenge was access to the participants. Most of the participants in the rural areas did not keep their phones on due to limited access on the phone battery services in the village. Additionally, whenever, I made an appointment with the participants and would want to confirm by making a follow-up call on the appointment date, I would find most of their phones off. Some participants would give the reasons that, since, no one calls them, there was no reason leaving it on. Other participants explained that, they had no problem with their phones being off, after all, they already knew the date I was scheduled to meet them. While to them it was not an issue, it made my fieldwork a bit challenging, although I always went to the participants on the agreed dates. 


\section{References}

Akello, J. A., Lutwama-Rukundo, E., \& Musiimenta, P. (2017). Functional adult literacy: An alternative gateway to grassroots women's improved income generation in Lango Subregion, Northern Uganda. Adult Education Quarterly, 67(2), 79-96.

Akyeampong, K. (2009). Revisiting Free Compulsory Universal Basic Education (FCUBE) in Ghana. Comparative Education, 45(2), 175-195.

Blunch, N.-H. (2013). Staying Alive: Adult Literacy Programs and Child Mortality in Rural Ghana. World Development, 42, 114-126.

Creswell, J. (2013). Research Design: Qualitative, Quantitative, and Mixed Methods Approaches: Sage Publications.

(2007). Qualitative Inquiry and Research Method: Choosing Among Five Approaches (2nd ed.): Thousand Oaks, CA: Sage.

Denscombe, M. (2014). The Good Research Guide: for Small-Scale Social Research Projects: McGraw-Hill Education (UK).

DiCicco-Bloom, B., \& Crabtree, B. F. (2006). The Qualitative Research Interview. Medical Education, 40(4), 314-321.

Findsen, B., \& Formosa, M. (2016). International Perspectives on Older Adult Education. Hamilton, New Zealand: Springer.

Fossey, E., Harvey, C., McDermott, F., \& Davidson, L. (2002). Understanding and Evaluating Qualitative Research. Australian and New Zealand journal of Psychiatry, 36(6), 717-732.

Freire, P. (1970). Pedagogy of the Oppressed, Trans. Myra Bergman Ramos. New York: Continuum. (1987). Literacy: Reading the Word and the World. Great Britain: Routledge.

Goldkuhl, G. (2012). Pragmatism vs Interpretivism in Qualitative Information Systems Research. European Journal of Information Systems, 21(2), 135-146.

Hanemann, U. (Ed.). (2017). Functional Adult Literacy (FAL) Programme, Uganda. UNESCO Institute for Lifelong Learning.

Hasaba, S. (2012). Education for All: Reflecting on Adult Literacy Learning for Socio-Economic Development in Uganda. Academic Research International, 2(2), 205.

Hesse-Biber, S. N. (2013). Feminist Research Practice: A Primer: A Primer: Sage Publications.

Imam, H. S. H., Chohan, F. A., Murtaza, M., Qamar, I., Zahra, F. T., Shahab, A., . . Ismail, W. (2017). How Illiteracy Affects the Health of Women and their Children in PMC Colony F Block. APMC 2017;11(2):9499.

Kabeer, N. (2005). Gender Equality and Women's Empowerment: A Critical Analysis of the Third Millennium Development Goal 1. Gender \& Development, 13(1), 13-24.

(2012). Women's Economic Empowerment and Inclusive Growth: Labour Markets and Enterprise Development. International Development Research Centre. London, UK: Centre for Development Policy \& Research, School of Oriental \& African Studies, University of London.

Kotsapas, A. (2010). Adult Literacy and Women's Empowerment: Exploring the Contribution of a Non-Formal Adult Literacy Programme to Women's Empowerment in Aileu, Timor Leste: A Thesis Presented in Partial Fulfilment of the Requirements for the Degree of Master of Philosophy in Development Studies at Massey University, Albany, Manawatu [Ie Manawatu], New Zealand.

Langer, A., Meleis, A., Knaul, F. M., Atun, R., Aran, M., Arreola-Ornelas, H., . . Caglia, J. M. (2015). Women and Health: The Key for Sustainable Development. The Lancet, 386(9999), 1165-1210.

Marshall, C., and G. B. Rossman. (2011). Designing Qualitative Research. 5th ed. Thousand Oaks, CA: Sage.

Mason, J. (2018). Qualitative Researching: Sage Publications.

Merriam, S. B., \& Kee, Y. (2014). Promoting community wellbeing: The case for lifelong learning for older adults. Adult Education Quarterly, 64(2), 128-144.

MoGLSD. (2007). Strengthening Literacy Practices in Uganda Through Funtional Adult Literacy Education. 
Kampala,Uganda: MoGLSD.

(2015). Uganda National Adult Literacy Policy. Ministry of Gender, Labour and Social Development.

Niraula, A. (2011). Rethinking the Role of Literacy Programs in Women's Empowerment: A Study of Women Literacy Program and National Literacy Campaign, Manohara Nayabasti, Nepal.

Nussbaum Martha, C. (1999). Sex and Social Justice: Oxford University Press.

(2001). Women and Human Development: The Capabilities Approach (Vol. 3). United Kingdom: Cambridge University Press.

Obeng-Odoom, F. (2013). Africa's Failed Economic Development Trajectory: A Critique. African Review of Economics and Finance, 4(2), 151-175.

Okech, A., \& Carr-Hill, R. A. (2001). Adult Literacy Programs in Uganda. United States of America: World Bank Publications.

Olaleye, F. (2008). Empowering Women Through Education. Education for Millennium Development. Essays in Honour of Professor Michael Omolewa (155 -165). 2. U.K. Safari Books Limited.

Oyitso, M., \& Olomukoro, C. (2012). Enhancing Women's Development Through Literacy Education in Nigeria. Review of European Studies, 4(4), 66.

Rogers, A. (2008). Report of Consultancy on Functional Adult Literacy Programme in Kalangala and Buvuma Islands Provided by The Government of Uganda Ministry of Gender, Labour and Social Development and Supported by ICEIDA.

Rothman, R. L., Yin, H. S., Mulvaney, S., Homer, C., \& Lannon, C. (2009). Health Literacy and Quality: Focus on Chronic Illness Care and Patient Safety. Pediatrics, 124(Supplement 3), S315-S326.

Rule, P., and V. John. (2011). Your Guide to Case Study Research. Pretoria: Van Schaik.

Sen, A. (1999). Development as Freedom. New York, NY (EUA).: Anchor Books.

Shields, W. C., McDonald, E. M., McKenzie, L. B., \& Gielen, A. C. (2016). Does Health Literacy Level Influence the Effectiveness of a Kiosk-Based Intervention Delivered in the Pediatric Emergency Department? Clinical Pediatrics, 55(1), 48-55.

Sleap, B. (2010). Discrimination Against Older Women in Uganda. HelpAge International, Uganda Reach the Aged Association, Committee on the Elimination of Discrimination against Women. Kampala: HelpAge International.

Stromquist, N. (2016). Adult Literacy and Women: A Present Account. Dialogues in Social Justice: An Adult Education Journal, 1(1).

UBOS. (2016). Uganda Bureau of Statistics 2016, The National Population and Housing Census 2014 - Main Report, Kampala, Uganda Kampala, Uganda.

(2017). The National Population and Housing Census 2014 - Area Specific Profile Series, Kampala, Uganda.

UIS. (2017). Literacy Rates Continue to Rise from One Generation to the Next, UNESCO Institute for Statistics. Retrieved from http://uis.unesco.org/sites/default/files/documents/fs45-literacy-rates-continue-risegeneration-to-next-en-2017_0.pdf

U1 Haq, M. (1995). Reflections on Human Development. New York: Oxford University Press.

UNESCO. (1974). The Experimental World Literacy Programme and its Global Evaluation. Retrieved from http://unesdoc.unesco.org/images/0001/000122/012286eb.pdf

(2015a). Education 2030: Towards Inclusive and Equitable Quality Education and Lifelong Learning for All. World Education Forum. Retrieved from http://unesdoc.unesco.org/images/0024/002456/245656e.pdf (2015b). Education for All 2000-2015: Achievements and Challenges. France. (2021). Literacy. Retrieved from https://en.unesco.org/themes/literacy (2013). Teaching and Learning: Achieving Quality for All, Global Monitoring Report 4/4: Paris: UNESCO.

Wetzel, J. W. (2016). The World of Women: In Pursuit of Human Rights: Springer. WHO. (1986). The Ottawa Charter for Health Promotion, Geneva. Retrieved from 
Yin, R. (2013). Case Study Research: Design and Methods: Sage Publications Notes

Judith Abal Akello (Ph. D) is a Senior Lecturer and Head of Department at Lira University, Northern Uganda in the Faculty of Management Science, Business Management Department. Judith won a DAAD (German Academic Exchange Service) scholarship to study at Makerere University where she received her PhD on "Unlocking The Socio- Economic Development Potentials: Women's Experiences of Functional Adult Literacy (FAL) in Apac District, Northern Uganda". She holds Master of Arts in Education and International Development from University of London (MAEID) under Commonwealth Scholarship; Master in Business Administration (MBA)-Finance and BA in Education-Business from Makerere University respectively. Her special research interest includes: women and adult literacy, women's socio-economic development, girls' education, school dropouts; quality of education; policy in education, micro-finance, women's poverty eradication, vocational education and health promotion. Judith is a member of East African Network of Development and International Connections in Education and Development.

Peace Musiimenta (Ph. D) is a lecturer and researcher at the School of Women and Gender Studies, Makerere University and she is a trainer on Gender Responsive Researchers Equipped for Agricultural Transformation (GREAT) course by Makerere University and Cornell University. Peace won a scholarship to study at Makerere University in collaboration with the University of Tromso, Norway where she completed her PhD on "Redefined Subordination: Interrogating Educated Women's Lived Experiences in Contemporary Urban Uganda". Peace holds a PhD in Gender studies, Masters in Women Studies and a certificate in Professional Development Programme for Gender Trainers. Peace is passionate about gender and education; women's socio-economic empowerment as well as women and engagement in social economic activities. Peace also coordinates Study Abroad Programmes Gender and Development elective at the School of International training (SIT), and represents the School of Women and Gender Studies on the Uganda Women's network (UWONET), she is also a member of the College of Humanities and Social Sciences (CHUSS) COVID-19 Task force and E-Learning coordinator for the School of Women and Gender Studies (SWGS). 